\title{
THE EFFECTIVENESS OF THE MOST USED TECHNIQUES IN PATIENTS WITH DEGENERATIVE CERVICAL DISEASE
}

\author{
A EFICÁCIA DAS TÉCNICAS MAIS UTILIZADAS EM PACIENTES COM DOENÇA \\ DEGENERATIVA CERVICAL
}

\section{LA EFICACIA DE LAS TÉCNICAS MÁS UTILIZADAS EN PACIENTES CON ENFERMEDAD CERVICAL DEGENERATIVA}

\author{
Lizandra Gagliardi Kalıl Debs, ${ }^{1}$ André Evaristo Marcondes Cesar, ${ }^{1}$ Luciano Miller Reis Rodrigues, ${ }^{1}$ Fernanda Amate Lopes, ${ }^{1}$ Marina Rosa Filezio ${ }^{1}$ \\ 1. Hospital IFOR, São Bernardo do Campo, SP, Brazil.
}

\begin{abstract}
The objective of this study was to discuss the three main surgical techniques currently applied in the treatment of degenerative cervical discopathy and their repercussions on patient quality of life. We considered the impact of the surgical techniques applied to the quality of life of 24 patients who underwent surgery during the period from 2010 to 2017 using the Oswestry and SF-36 scales. With the application of the questionnaires we observed, through the applicability and analysis of the quality of life results indicated in the questionnaires, that pain improvement and a reduction in work and daily activity disability were more effective with cervical arthroplasty. We concluded that with the individualization of surgical treatment, that is, through the choice of the surgical technique most appropriate for the clinical condition, the postoperative recovery and consequently the quality of life of the patient are enhanced. Level of evidence IV; Descriptive study.
\end{abstract}

Keywords: Spondylosis; Surgery; Spine; Neck Pain; Intervertebral Disc.

\section{RESUMO}

A presente pesquisa pretende discutir as três principais técnicas cirúrgicas aplicadas atualmente no tratamento da discopatia degenerativa cervical e a sua repercussão na qualidade de vida do paciente. Considerou-se o impacto das técnicas cirúrgicas aplicadas na qualidade de vida de 24 pacientes submetidos à cirurgia no período de 2010 a 2017, através da escala de Oswestry e do SF-36. Com a aplicação do estudo pudemos observar que através da aplicabilidade e análise dos resultados apontados nos questionários de qualidade de vida, a melhora da dor e a diminuição da incapacidade laboral e diária foram mais eficazes na artroplastia cervical. Concluiu-se que com a individualização do tratamento cirúrgico, ou seja, através da escolha da técnica cirúrgica mais apropriada ao quadro clínico, potencializa-se a recuperação pós-operatória e, consequentemente, a qualidade de vida do paciente. Nível de evidência IV; Estudo Descritivo.

Descritores: Espondilose; Cirurgia; Coluna Vertebral; Cervicalgia; Disco Intervertebral.

\section{RESUMEN}

La presente investigación pretende discutir las tres principales técnicas quirúrgicas aplicadas actualmente en el tratamiento de la discopatía degenerativa cervical y su repercusión en la calidad de vida del paciente. Se consideró el impacto de las técnicas quirúrgicas aplicadas en la calidad de vida de 24 pacientes sometidos a cirugía en el período de 2010 a 2017, a través de la escala de Oswestry y del SF-36. Con la aplicación del estudio pudimos observar que a través de la aplicabilidad y análisis de los resultados apuntados en los cuestionarios de calidad de vida, la mejora del dolor y la disminución de la incapacidad laboral y diaria fueron más eficaces en la artroplastia cervical. Se concluyó que, con la individualización del tratamiento quirúrgico, o sea, a través de la elección de la técnica quirúrgica más apropiada al cuadro clínico, se potencializa la recuperación postoperatoria y, consiguientemente, la calidad de vida del paciente. Nivel de evidencia IV; Estudio descriptivo.

Descriptores: Espondilosis; Cirugía; Columna Vertebral; Dolor de Cuello; Disco Intervertebral.

\section{INTRODUCTION}

Degenerative disc disease is a change at the cellular level that causes the aging and loss of disc substance in any spinal segment. Degenerative disease of the cervical disc has different etiologies that may have their origin in various clinical conditions, such as disc herniations, vertebral stenosis, and spondylosis. ${ }^{1}$

Because it is a highly complex disease, the factors involved in its genesis can be divided into two distinct groups: the static factors that are related to reduction of the sagittal diameter of the spinal canal [congenital stenosis of the spinal canal $(<13 \mathrm{~mm}$ anterior-posteriorly), congenital cervical anomalies, such as the Klippel-Feil syndrome, disc herniation, the formation of osteophytes in the vertebral body, hypertrophy of the facet and uncovertebral joints, and calcification of the posterior longitudinal ligament and the ligamentum flavum] and the dynamic factors that are related to abnormal forces that act on the movement inherent to the cervical spine..$^{2,3}$

The reduction of the sagittal diameter of the spinal canal, the 
first degenerative phenomenon of the disease, begins with the loss of height and elasticity of the disc. The loss of water and proteins caused by age makes the nucleus pulposus of the disc become smaller and more fibrous, possibly resulting in its herniation between the thinner layers of the annulus fibrosus (principally in the dorsal region) and the loss of cervical lordosis due to the flattening of the cervical disc. ${ }^{2,4}$

As a consequence of the events described above, excessive growth of bone in the dorsal and ventral parts of the vertebral bodies occurs producing osteophytes that expand the width of the vertebra and, together with the increase in axial load caused by the loss of disc height and disc herniation, the uncovertebral and facet joints undergo hypertrophy along with the posterior longitudinal ligament and the ligamentum flavum and a vicious cycle of osteophyte formation and narrowing of the spinal canal occurs. ${ }^{2}$

The dynamic factors are closely linked to movements of cervical flexion and extension that cause compression and repetitive microtraumas. In flexion movements, anterior stretching of the spinal cord over osteophytes and protruding discs and deformation of the lateral and ventral columns of the cervical spine occur, causing a reduction in the sagittal diameter of the spinal canal, while in extension movements dorsal compression of the spinal canal by the posterior longitudinal ligament and the ligamentum flavum occurs. ${ }^{2,4}$

These biomechanical cervical spinal changes caused by aging also lead to vascular ischemia in the gray and white mass of the spinal cord that occurs as a result of various elements, such as thickening of the anterior spinal artery and parenchymal arterioles, reduction of the arterial diameter due to foraminal stenosis, reduction in blood flow, and loss of endothelial cells that make up the spinal barrier at the cellular level due to direct endothelial damage secondary to inflammatory events, contributing to the appearance of the clinical and radiological picture of the patient. ${ }^{5}$

In published studies, degenerative cervical disc diseases are more common in patients with neurological dysfunction older than 55 years of age and they are more prevalent in males at a ratio of 3:2. ${ }^{6}$

The first symptoms of the disease are benign and tend to evolve insidiously and with little chance of spontaneous regression. The clinical status can unfold in three distinct or associated forms. Axial pain, one of the possible clinical conditions, presents as a limitation of cervical movements associated with muscular contraction and radiation to the upper limbs. It may be chronic or episodic with remission. Radiculopathy manifests as loss of sensitivity, hyporeflexia, muscle atrophy, and fasciculations affecting mainly the $\mathrm{C} 6 / \mathrm{C} 7$ nerve roots. The most worrisome of the clinical conditions, myelopathy, typically presents as loss of manual dexterity, generalized muscle weakness, walking disturbances, and urinary urgency (that can evolve into incontinence), with the physical examination revealing positive Babinski and Hoffman signs, altered reflexes, paresthesia, spasticity, and motor deficit of varying intensity. ${ }^{6}$

When patients present the clinical conditions described above, the diagnosis must be confirmed using imaging examinations to document its existence, to describe its severity, and to exclude differential diagnoses that can make treating the disease difficult.

Although radiographs of the cervical spine have low specificity, they are the first diagnostic examinations to be requested due to their low cost and because they reveal changes in both symptomatic and asymptomatic patients. The main alterations visualized in the lateral incidence are reduced disc space, osteophyte formation, and reduced medullary space, while oblique incidences show the degree of foraminal stenosis and dynamic incidences (flexion/extension) define the degree of instability. Magnetic resonance, the most important of all the examinations, detects the reduction of the spinal canal, medullary compression, and signs of intramedullary abnormalities that have a direct influence on the modality of treatment and prognosis of the patients. Computed tomography defines and analyzes the cervical bone anatomy, complementing magnetic resonance imaging. And finally, the cerebrospinal fluid, which is principally important for the detection and/or exclusion of differential diagnoses, especially demyelinating diseases, infections, and meningeal tumors. ${ }^{6-8}$
There are several diseases that can mimic the clinical conditions of degenerative cervical disease, which hinders early diagnosis and impairs the postoperative outcome and subsequent recovery of the patient.6,8

Rheumatological diseases, including sarcoidosis, Sjogren's syndrome, systemic lupus erythematosus, rheumatoid arthritis, and ankylosing spondylitis are differentiated from degenerative cervical disease by their inflammatory and autoimmune nature, by having interspersed periods of remission and exacerbation, and by radiographical examinations and laboratory test findings with specific markers for each disease cited. ${ }^{8}$ Metabolic causes, especially copper and vitamin B12 deficiencies, also should be excluded if the imaging examinations do not reveal a structural cause for the clinical condition of the patient. ${ }^{4}$ Myelinating diseases (multiple sclerosis and amyotrophic lateral sclerosis) are differentiated from degenerative cervical disease by magnetic resonance presenting demyelination plaques and changes in the electroneuromyography, since the initial clinical status of the patient and its progression are usually similar. ${ }^{6}$

After detection of the disease, it is imperative to begin multidisciplinary treatment and outpatient follow-up, considering the severity of the patient's clinical status and imaging examination findings for therapeutic planning and better adaptation of the patient to their illness.

The main goals of treatment, whether surgical or not, are to control pain, limit disruptions in their daily lives, and rehabilitate them for their work activities, reminding the patient that the recovery process is slow and does not always meet their expectations depending on the severity of their disease.

Initially, conservative treatment and outpatient follow-up of the patient should begin with changes in lifestyle; avoidance of repetitive physical exertion; guidance towards a process of weight loss; preventing any type of fall or trauma in the cervical region, as it can accelerate the appearance of neurological dysfunction; motor physical and analgesic therapies for better adjustment of the muscles to the illness; analgesic medication combined or not with a cervical collar for pain crises; neuromodulator medication, such as gabapentin and pregabalin, both acting on the pain receptors, though pregabalin being superior due to its better absorption by the organism (reducing daily doses) and its lower rate of complication compared to gabapentin, and rest, which must be prescribed parsimoniously, since after 72 hours it can contribute to muscle atrophy. ${ }^{8}$

In cases of conservative treatment failure (duration of at least six months), progressive neurological dysfunction, signs of medullary deterioration revealed by imaging examinations (reduction of the medullary space, myelomalacia, or the presence of kyphotic deformity), persistent pain, and muscle weakness, the indication of a surgical procedure is imperative because surgical decompression improves the neurological dysfunction, the functional status, and the quality of life of the patient. ${ }^{6,9,10}$

\section{METHODS}

By conducting a literature review, we developed an explanation of the three surgical techniques currently most often used in the treatment of degenerative cervical discopathy (cervical arthrodesis, cervical arthroplasty, and hybrid cervical surgery) in patients who have chronic cervical pain, have undergone outpatient palliative treatments and follow-up, and were submitted to surgical treatment of the disease.

The success of these techniques was analyzed and compared through the administration of quality of life questionnaires (SF-36 and Oswestry) at four different critical moments during the evolution of the clinical condition and postoperative recovery of the patient: six months before surgery and at six months, one year, and two years after the procedure. These questionnaires were administered to 24 patients between the ages of 33 and 60 years, equally distributed among the surgical procedures studied and performed during the period from 2010 to 2017.

All patients included in the study signed the Informed Consent Form after approval of the study by the Institutional Review Board of the Hospital IFOR (C.A.A.E: 13842913.5.0000.0082). 
For the applicability of the SF-36 and the Oswestry Scale, we searched the bibliographical sources for a suitable model in which the questions would assist the progressive follow-up of the patient's clinical condition over a two-year period.

For the calculations necessary for the study, we used an application available online that generated quantitative clinical status improvement results from the responses obtained from the questionnaires and simultaneously created a data spreadsheet in Microsoft Excel 2013 and IBM SPSS (Statistical Package for Social Sciences) version 24.0, with tabulations of statistical data for comparison of the techniques studied.

And finally, we used Friedman's Test to compare the statistical differences among patients submitted to the same surgical technique and the Wilcoxon Signed Rank Test to identify the statistical relevance obtained in the SF-36 and Oswestry Scale domains and compare them at each moment of postoperative recovery proposed in the study.

\section{RESULTS}

When performing the quantitative analysis of the data obtained from the SF-36, we noted that the patients submitted to the hybrid cervical technique improved in three domains (limitation of physical aspects, vitality, and mental health); those submitted to the cervical arthroplasty technique had positive recovery in six domains (limitation of physical aspects, general state of health, vitality, limitation of emotional aspects, mental health, and social aspects); and those who underwent cervical arthrodesis had no positive improvement in any of the questionnaire domains.

Pain, a domain addressed in the SF-36, not only in terms of intensity but also in terms of how it affects the patient's usual activities, improved rapidly and significantly during the study period with the cervical arthroplasty technique, while the hybrid cervical technique was the surgical technique that had the lowest performance in that domain, as the patients submitted to this technique only reported significant improvement two years following the surgical procedure. Six months following the surgical procedure, cervical arthrodesis was equal to cervical arthroplasty in terms of pain improvement. (Figure 1)

The general state of the patient's health, an SF-36 domain that analyzes the patient's confidence in their treatment and in their health, showed improvement after one year with cervical arthroplasty, followed by hybrid surgery. The cervical arthrodesis technique was less reliable from the patient perspective as it only reached $70 \%$, as shown in the graph (Figure 2).

Regarding the patient's mental health, there was significant improvement with all techniques analyzed one year after the surgical procedure, however, cervical arthroplasty had the fastest improvement (six months following surgery), while the slowest technique to achieve significant improvement in this SF-36 domain was cervical arthrodesis.

The SF-36 domains in which the hybrid cervical technique stood

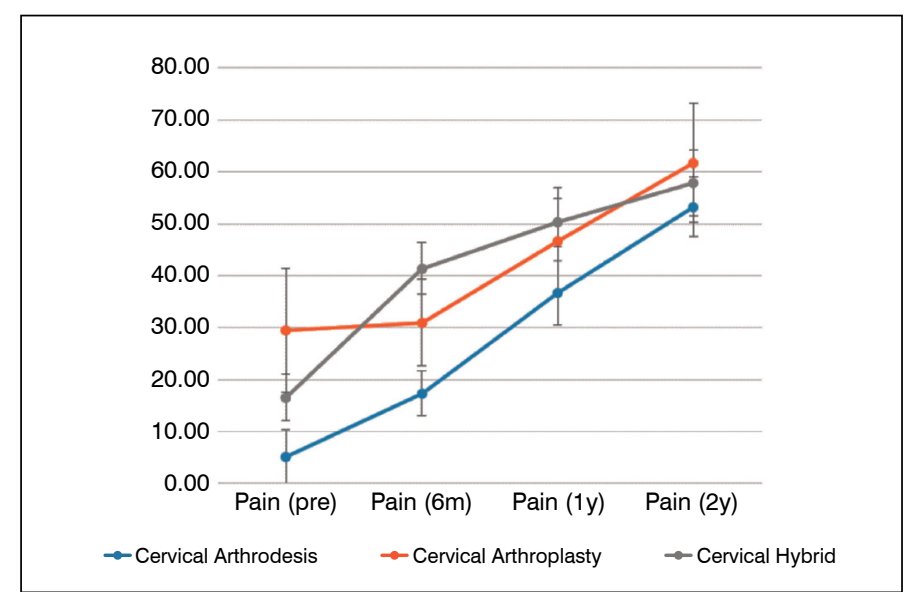

Figure 1. Comparative analysis of the level of pain applied in the three techniques analyzed. out compared to the two other techniques studied were vitality, in which patient recovery surpassed that obtained with cervical arthroplasty and arthrodesis at eight months after surgery, and the social aspect, in which the hybrid technique already showed significant improvement over the other techniques at six months after surgery. (Figures 3 and 4)

Finally, when analyzing the Oswestry Scale, which describes and classifies the degree of disability of the patient due to their disease, it is noteworthy that all the surgical techniques included in the study reduced the level of disability reported by the patients during their preoperative consultation, the most effective being cervical arthroplasty and the least effective being cervical arthrodesis. (Figure 5)

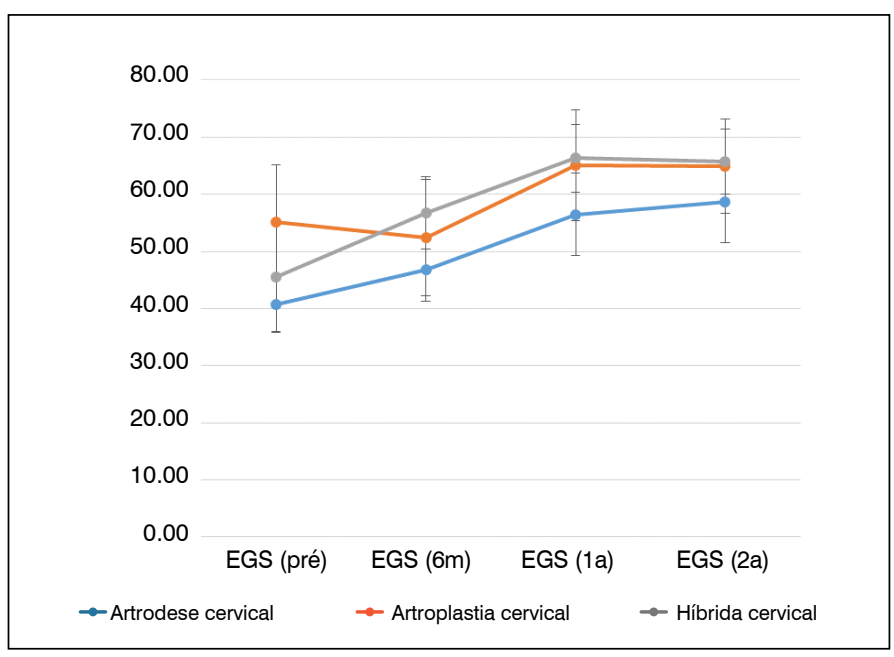

Figure 2. General health status.

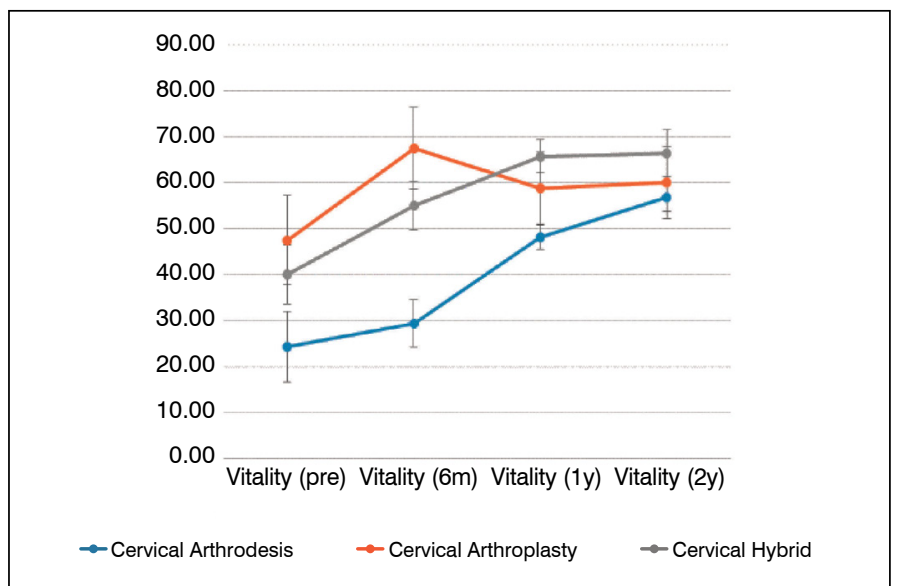

Figure 3. Comparative analysis of the vitality of the three surgical techniques.

\section{DISCUSSION}

The main goals of surgical treatment are to remove compressive forces, decompress the spinal cord, make room for better spinal cord recovery, stabilize the affected cervical segments, and prevent future cervical deformity caused by degenerative disease.

When choosing the most appropriate surgical technique for a clinical case, the age of the patient, the severity of their clinical condition assessed through imaging and the symptoms presented, their level of work and daily activities, associated comorbidities, and the cervical levels affected by the disease must all be considered so that the surgical treatment can be adapted to the priority needs of the patient and improve their functional status.

Since 1950, the most widely used technique for cervical radiculopathy and myelopathy caused by degenerative cervical disease remains anterior approach arthrodesis and cervical decompression, 


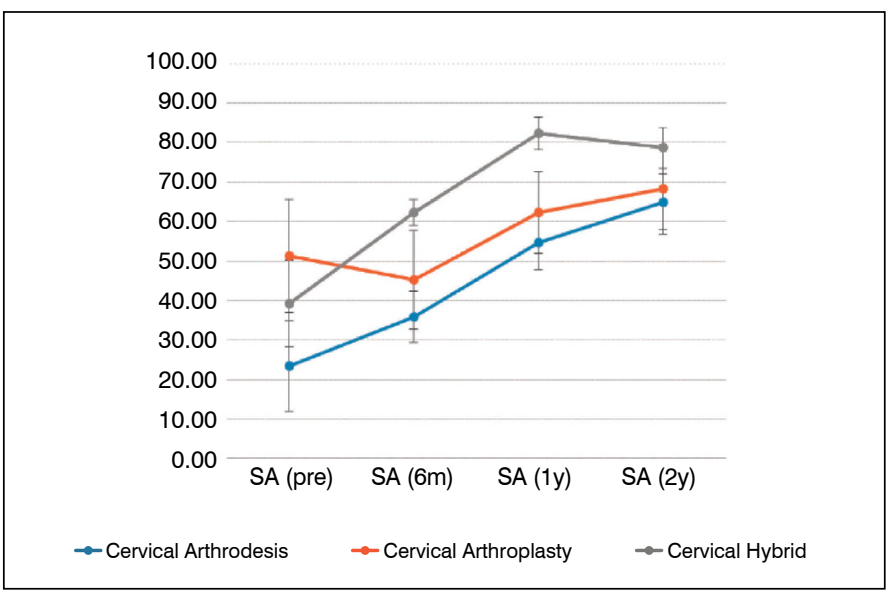

Figure 4. Comparative analysis of the social aspect of the three surgical techniques.

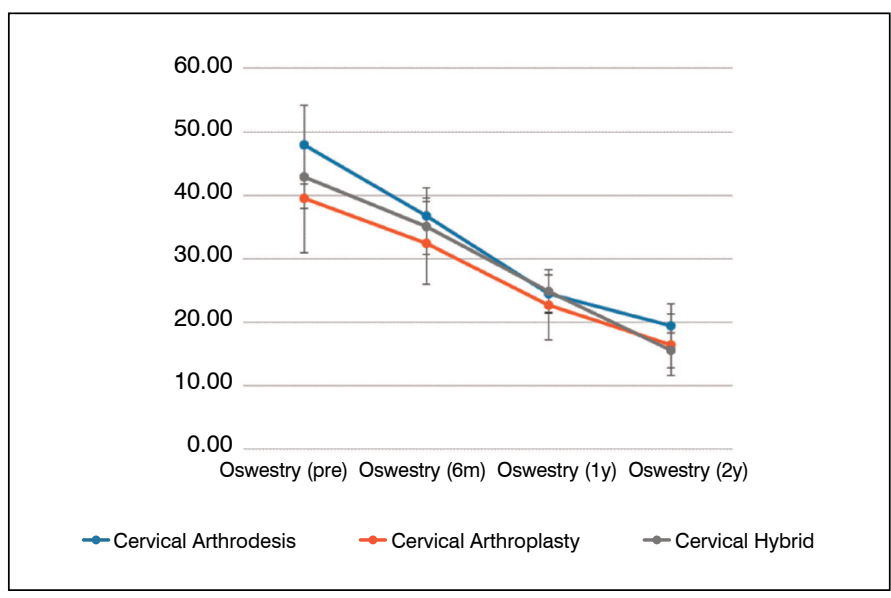

Figure 5. Final Analysis of the Oswestry Scale.

since it is the procedure that best achieves decompression and stabilization of the affected levels. However, fusing the cervical levels involved eliminates the natural movement of these segments, increasing the mobility, stress, and intradiscal pressure of the adjacent levels, leading to pseudoarthrosis, limitation of cervical movements, and the adjacent level syndrome. This set of biomechanical changes leads to a return and/or worsening of the clinical picture (mainly cervical pain refractory to analgesic medications) associated with a decrease in functional recovery, requiring new surgical approaches not always satisfactory for the surgeon and their patient..$^{11-14}$

In order to avoid the harmful effects of the adjacent level syndrome, reduce the surgical reoperation rates, reduce intraoperative time and other disadvantages inherent to cervical decompression and cervical arthrodesis mentioned above, the technique of anterior cervical arthroplasty was created, which consists of replacing the degenerated cervical disc with an artificial cervical prosthesis preserving the movement inherent to the segment approached, reestablishing cervical alignment and maintaining intradiscal pressure, avoiding biomechanical changes capable of accelerating the degeneration of the levels adjacent to the surgical approach proposed to the patient. ${ }^{12,13}$ (Figure 6)

The patients most likely to benefit from using this cervical arthroplasty technique are those with mature bone age from $\mathrm{C} 3$ to $\mathrm{C} 7$, with nerve root pain, soft disc herniation, loss of disc weight, osteophytes, intact posterior longitudinal ligament, and mild facet joint arthrosis.

Taking these eligibility criteria into account, the classic contraindications described for the use of cervical arthroplasty are loss of disc height greater than $50 \%$, subluxation greater than two or three $\mathrm{mm}$ in dynamic cervical radiographic incidences, a previous cervical laminectomy, structural instability, recent history of cervical spine

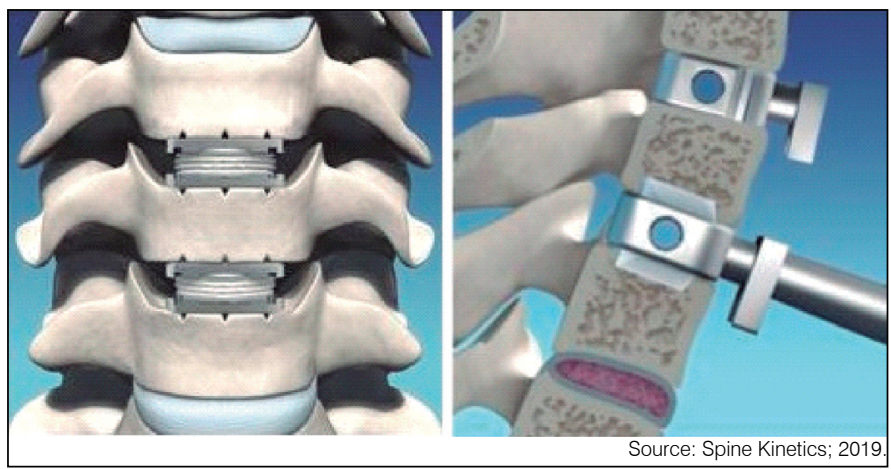

Figure 6. M6 Cervical Prosthesis.

infection, ankylosing spondylitis, rheumatoid arthritis with cervical instability, ossification of the posterior longitudinal ligament, diffuse idiopathic skeletal hyperostosis and metabolic diseases that impair bone quality, myelopathy from compression of the vertebral body, presence of severe facet joint arthrosis, and morbid obesity that contraindicated the anterior approach to the cervical spine. ${ }^{12,13}$

The main complications associated with this surgical technique may include persistent cervical pain, which can result from inadequate foraminal decompression in surgery; kyphotic deformity or severe facet joint disease; failure or breakage of the device; diagnostic error from not identifying the differential diagnoses that can mimic the clinical conditions of degenerative cervical disease; dysphagia; and heterotopic calcification (its rate increases considerably with the use of non-steroidal anti-inflammatories during the patient's postoperative recovery). These complications, especially persistent cervical pain, are usually more common in patients who have more serious clinical and radiological conditions in preoperative planning. ${ }^{15}$

In cases of multiple-level degenerative cervical disease, where each cervical disc level has a different degree of degeneration (collapsed intradiscal space, facet joint degeneration, and the presence of osteophytes or total loss of normal segment movement), the concept of a hybrid surgery was developed, which consists of a combination of the surgical techniques of arthroplasty with cervical arthrodesis such that each level can be treated individually with the technique most indicated for its degree of degeneration, avoiding unnecessary stress on the levels adjacent to the surgical approach and consequently reducing postoperative complications that impair the functional recovery of the patients. Although this surgical technique is better suited to the condition of the patient, it has disadvantages, such as increased surgical time and intraoperative blood loss, an increased rate of heterotopic ossification, the possibility of vertebral body fractures, dislocation of the implant (if not properly placed), and the possible loss of cervical lordosis. ${ }^{13,16-18}$

In addition to choosing the appropriate surgical technique for the patient's clinical and radiographical condition, other factors also influence and are considered predictors of the outcome and quality of life of the patient after the surgical procedure. The factors that predict poor prognosis of surgical outcomes can be divided into two distinct groups: those related to the patient and those related to the imaging examinations (magnetic resonance and computed tomography). ${ }^{3}$

Predictors of poor postoperative prognosis related to the imaging studies conducted are the presence of a T2 hypersignal in the magnetic resonance, mainly associated with multiple-level disease; a decrease in the intramedullary $\mathrm{T} 1$ signal, and a reduction of the sagittal diameter of the spinal canal in compression. The predictive factors related to the patients are age, as the older the patient the greater the chance of developing postoperative complications, and the duration of the signs and symptoms of compression. 3,10

To describe, compare, and analyze the quality of life of the patients and the postoperative results and repercussions of the surgical techniques previously described and analyzed, we used two quality of life questionnaires: the SF-36 (Medical Outcomes Study 36-Item Short-Form Health Survey) and the Oswestry Scale 
(The Oswestry Disability Index (ODI)), which assist the surgeon to identify factors that may influence the postoperative results of their patients and to choose the most appropriate treatment for their particular clinical and radiological conditions.

The SF36 (Medical Outcomes Study 36-Item Short-Form Health Survey), developed by The Health Institute, is a generic quality of life assessment tool, easy for the patient to understand and complete and easy for the examiner to administer. ${ }^{19}$

It was validated for Brazilian Portuguese in 1999 by Cicconelli et al. and consists of a multidimensional questionnaire with 36 items organized into 8 scales or domains, which are physical functioning, physical aspects, pain, general state of health, vitality, social aspects, emotional aspects, and mental health. A final score from 0 (zero) to 100 (one hundred) is presented, obtained by means of the RawScale calculation, where zero corresponds to the worst general state of health and 100 corresponds to the best state of health. ${ }^{19}$

Obtaining and interpreting the SF-36 results depends on the meaning of each domain, since each one of them addresses a different aspect of the patient's quality of life and how he/she behaves when faced with the difficulties that the clinical and radiological conditions of his/her illness situation present.

Physical functioning is intended to measure limitations that range from performing minor physical activities, such as bathing or getting dressed, to intermediate activities, such as lifting or carrying groceries, climbing stairs, or walking certain distances, to more demanding activities. Low scores in this dimension indicate that the person is very limited in performing all physical activities, including bathing or getting dressed, for health reasons and high scores mean that the person can perform all types of physical activity, including the most demanding, without limitations for health reasons. Physical functioning measures limitations on the type and the amount of work performed due to physical problems. This includes limitations on the type of tasks performed regularly, the need to reduce the amount of work, and the difficulty of performing tasks. Low scores in this dimension indicate problems with work or other daily activities as a result of physical health and high scores indicate that the person does not have trouble performing work or other daily activities as a result of physical health. The domain related to pain reflects not only its intensity and the discomfort it causes, but also the extent to which it interferes with common activities. The emotional aspects domain measures impact to health and to the type and the amount of work performed caused by emotional problems, as well as the need to reduce the amount of work and the difficulty of performing the tasks. Low values in this subscale indicate that the person has difficulties with work or other daily activities due to emotional problems, while high values indicate that the person does not have difficulties with work or other daily activities due to emotional problems. The general state of health aims to measure the concept of general health perception, including not only current health, but also resistance to disease and healthy appearance. Low values indicate that the person rates their health as poor and believes that it is likely to worsen, while high values indicate that the person rates their health as excellent. The domain of vitality includes levels of energy and fatigue, with low scores meaning that the person feels tired and exhausted most of the time, while high scores indicate that the person feels animated and full of energy. The social aspect is intended to capture the quantity and quality of social activities, as well as the impact of physical and emotional problems on the social activities of the respondent. Low scores indicate that emotional and physical problems interfere extremely and frequently with normal social activities and high scores indicate that the person performs normal social activities without the interference of physical or emotional problems. And the last domain, mental health, includes questions relating to four of the most important dimensions of mental health, namely anxiety, depression, loss of control in behavioral and emotional terms, and psychological well-being. Low values indicate that the person is always nervous and depressed, while high values indicate that the person feels at peace, happy, and calm. ${ }^{19}$

The Oswestry Disability Index (ODI) is a disease-specific tool recommended for the evaluation of spinal disorders. John O'Brien began to develop this scale in 1976 when patients were initially interviewed by an orthopedic surgeon (Stephen Eisenstein) together with an occupational therapist (Judith Couper). The questionnaire was published in 1980 and was widely disseminated in 1981 at the meeting of the International Society for the Study of the Lumbar Spine in Paris. ${ }^{19}$

The ODI is an ordinal tool, in which ten criteria are analyzed (pain intensity, personal care, lifting weight, reading, the presence of headache, concentration, work, driving, sleeping, and recreational activities) with six response choices for each criterion. The total score varies from 0 to 100, where zero corresponds to normal function and 100 indicates severe disability. For each question, zero is normality and five is the greatest functional change. The sum of the 10 questions divided by five, multiplied by the number of questions answered, and then multiplied by 100 is the ODI score. ${ }^{19}$

The results of the Oswestry scale are divided into five categories: minimum disability (0 to 20\%: The patient can perform most of their daily activities. Most of the patients in this group have sedentary occupations (typist, driver) and the treatment indicated is improvement of the paravertebral musculature, guidance on squatting and lifting movements, and most importantly, attention to posture in all movements performed in daily and work activities.); moderate disability (21 to 40\%: The patient experiences more pain and difficulty sitting, getting up, and standing and both travel and social life are more difficult. Personal care, sexual activity, and sleep are not seriously affected and conservative treatment is most often indicated.); severe disability (41 to $60 \%$ : pain continues to be the main problem in this group, but daily activities are affected. The patients in this group require detailed investigation.), crippled (61 to $80 \%$ : Pain affects all aspects of the life of the patient. Surgical intervention is indicated in this group.); and the last group (81 to $100 \%$ : The patients in this group are either bedridden or are exaggerating when reporting their symptoms and clinical condition. Clinical history must be collected and a thorough clinical orthopedic examination must be conducted for patients belonging to this group). ${ }^{19}$

Although it is considered a versatile scale, easy and quick for the patient to fill out, it has sources of error that can influence the results obtained by the scale and consequently corrupt the postoperative evaluation and interpretation of the patient studied. ${ }^{19}$

The sources of error in the Oswestry scale that can affect obtaining and correctly interpreting the results regarding the postoperative recovery and the quality of life of the patient are the natural fluctuation of symptoms in the patient's clinical condition, inconsistencies in a patient's responses to questions pertaining to the questionnaire, improvement or worsening of the patient's clinical condition and symptoms due to the current treatment, the variety of versions of the scale in question, and differences in ODI results between males and females (Several researchers reported female scores as significantly higher when compared to those of males.). ${ }^{19}$

\section{CONCLUSIONS}

After analyzing and comparing the statistical data obtained from the results of the quality of life questionnaires, administered to patients selected for a study that encompassed a wide age range and both sexes, the efficiency of cervical arthroplasty over the other techniques studied in most of the subjects covered by the SF-36, particularly in the analysis of the significant reduction of the limitations of the emotional and physical aspects and the improved physical capacity of the patient, and by the Oswestry scale, showing a significant reduction in their initial disability, were noteworthy.

In addition to the choice of the surgical technique most suitable for the patient, other factors were determinants for evolution and recovery following the surgical procedure: the severity of their 
radiological condition, demonstrated mainly by magnetic resonance imaging; the age of the patient; their comorbidities; the severity and duration of physical examination findings that demonstrate spinal cord distress due to compression; and the extent of the disease.

This leads us to conclude that the more individualized the treatment of the patient, that is, the more the seriousness of their symptoms, the more the severity of their imaging examination findings, their age and their comorbidities are examined, the better the patient's postoperative recovery and consequently their quality of life will be.

All authors declare no potential conflict of interest related to this article.

CONTRIBUTION OF THE AUTHORS: Each author made significant individual contributions to this manuscript. LGKD was the lead author of the research article. FAL revised the ABNT notes and performed the statistical data analysis. MRF collected and organized the data obtained from the quality of life questionnaires. LMRR and AEMC analyzed the radiographical images, reviewed the manuscript, approved the final version of the manuscript, and contributed to the intellectual concept of the study.

\section{REFERENCES}

1. Hubner AR, Mendes MR, Queruz JCF, et al. Avaliação do tratamento da discopatia degenerativa cervical pela artrodese via anterior utilizando placas associadas a cages ou cages em peek isoladamente. Coluna/Columna. 2011:10(4):300-4.

2. Shedid D, Benzel EC. Cervical spondylosis anatomy: pathophysiology and biomechanics. Neurosurgery. 2007;60(1 Suppl 1):S7-13

3. Toledano M, Bartleson JD. Cervical spondylotic myelopathy. Neurol Clin. 2013:31(1):287-305

4. Lebl DR, Bono CM. Update on the Diagnosis and Management of Cervical Spondylotic Myelopathy. J Am Acad Orthop Surg. 2015;23(11):648-60.

5. Karadimas SK, Gatzounis G, Fehlings MG. Pathobiology of cervical spondylotic myelopathy. Eur Spine J. 2015;24(suppl 2):132-8.

6. McCormack BM, Weinstein PR. Cervical spondylosis: An update. West J Med. 1996:165(1-2):43-51.

7. Baron EM, Young WF. Cervical spondylotic myelopathy: a brief review of its pathophysiology, clinical course, and diagnosis. Neurosurgery. 2007:60(1 suppl 1):S35- 41

8. TracyJA,BartlesonJD.Cervical spondylotic myelopathy. Neurologist. 2010;16(3):176-S7.

9. Tetreault L, Goldstein CL, Arnold P, Harrop J, Hilibrand A, Nouri A, et al. Degenerative cervical myelopathy: a spectrum of related disorders affecting the aging spine. Neurosurgery. 2015;77(Suppl 4):S51-67.

10. Emery SE. Cervical spondylotic myelopathy: Diagnosis and treatment. J Am Acad Orthop Surg. 2001;9(6):376-88.

11. Davis RJ, Nunley PD, Kim KD, Michael SH, Robert JJ, Hyun WB, et al. Two-leve total disc replacement with Mobi-C cervical artificial disc versus anterior discectomy and fusion: a prospective, randomized, controlled multicenter clinical trial with 4-year follow-up results. J Neurosurg Spine. 2015;22(1):15-25.
12. Zhao H, Duan LJ, Gao YS, Yang YD, Tang XS, Zhao DY, et al. What is the superior surgical strategy for bi-level cervical spondylosis-anterior cervical disc replacement or anterior cervical decompression and fusion? Medicine (Baltimore). 2018;97(13):e0005.

13. Zhang J, Meng F, Ding Y, Li J, Han X, Zhang X, et al. Hybrid surgery versus anterior cervical disc ectomyand fusion in multilevel cervical disc diseases: a meta-analysis. Medicine (Baltimore). 2016;95(21):e3621.

14. Rao MJ, Nie SP, Xiao BW, Zhang GH, Gan XR, Cao SS, et al. Cervical disc arthroplasty versus anterior cervical disc ectomyand fusion for treatment of symptomatic cervical disc disease: a meta-analysis of randomized controlled trials. Arch Orthop Trauma Surg. 2015;135(1):19-28.

15. Cody JP, Kang DG, Tracey RW, Wagner SC, Rosner MK, Lehman RA. Outcomes following cervical disc arthroplasty: a retrospective review. J Clin Neurosci. 2014;21(11):1901-4

16. Laratta JL, Shillingford JN, Saifi C, Riew KD. Cervical Disc Arthroplasty: A Comprehensive Review of Single-Level, Multilevel, and Hybrid Procedures. Global Spine J. 2018;8(1):78-83.

17. Healy AT, Sundar SJ, Cardenas RJ, Mageswaran P, Benzel EC, Mroz TE, et al. Zero-profile hybrid fusion construct versus 2-level plate fixation to treat adjacent-level disease in the cervical spine. J Neurosurg Spine. 2014;21(5):753-60.

18. Lu VM, Zhang L, Scherman DB, Rao PJ, Mobbs RJ, Phan K. Treating multi-level cervical disc disease with hybrid surgery compared to anterior cervical discectomy and fusion: a systematic review and meta-analysis. Eur Spine J. 2017:26(2):546-57.

19. Fairbank JCT, Pynsent PB. The Oswestry Disability Index. Spine (Phila Pa 1976). 2000;25(22):2940-53 